\title{
Climbing suppression: Passive avoidance in the turtle'
}

IRWIN M. SPIGEL 2 AND KENNETH ELLIS TEMPLE UNIVERSITY

\begin{abstract}
The persistent effort by the turtle Chrysemys to climb from a walled enclosure is utilized in a situation which allows for the study of passive avoidance in this species. A parametric examination of the effects of shock intensity on this behavior produced the expected gradients for two measures of avoidance acquisition, but failed to yield differences in extinction.
\end{abstract}

\section{Problem}

The aversive nature of walled confinement to turtles of the species Chrysemys picta has been previously reported by the author in connection with studies of detour learning (Spigel, 1964). When confined in such fashion, Ss are apt to spend much of their time attempting to climb out of the enclosure. The current experiment was designed to explore the possibility of utilizing this natural climbing response in the examination of passive avoidance in Chrysemys. Specifically, the suppression of this response as a function of shock intensity was investigated with apparatus in which the $S$ 's natural response produced the noxious contingency.

\section{Subjereis}

Twenty male and 10 female Chrysemys were employed. Ss were divided semi-randomly into five groups, the restriction being the assignment of two females to each. Ss were between 3 and $4 \mathrm{yr}$. of age as estimated from carapace length.

\section{Ipparatus}

A circular metabolism cage, $8-1 / 2$ in high and 8 in in diameter was wired into the circuit shown in Fig. 1. A mercury switch was taped to the forward decline of the $S^{\prime}$ 's carapace such that when a lie of approximately $20^{\circ}$ was attained, a shock circuit was completed by $\mathrm{S}$ between the floor and wire wall of the cage which had been insulated from one another. Closing the switch also simultaneously activated a clock. Both circuits were broken by a return of the $\mathrm{S}$ to the horizontal. In this manner, Ss received shock only while climbing, and a record of total climbing time (and seconds of shock) was obtained, Shock level was controlled by a variable transformer, A square screen, 14 in on a side and 12 in high surrounded the climbing cage. Flexible wire was used for the mercury switch connection and drawn upward through the wire cover of the cage with sufficient slack to allow complete freedom of movement for the S.

\section{Procedur o}

Five shock intensities were employed: $0,30,45,60$, and 90 volts $\mathrm{AC}$, one group of Ss exposed to each. Ss were given $1 / 2 \mathrm{hr}$. sessions daily in the apparatus until a criterion of one full session totally free of climbing

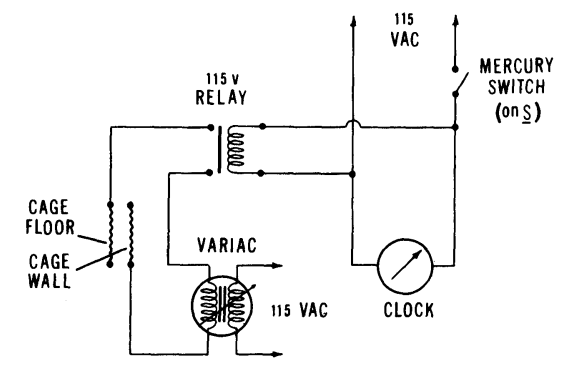

Fig. 1.

was attained. Five daily 1/2-hr. shock-free extinction trials follwed.

\section{Results}

Functions relating both number of trials to criterion and mean second's of climbing per trial to criterion, to shock level are shown in Fig. 2. One $S$ in the 0 volt (control) group failed to zero out and trials were arbitrarily halted after the 50th day. Analysis of variance across shock intensities are highly significant in the case of both acquisition measures $(\mathrm{F}=6.9, \mathrm{p}<.01$; $F=19.2$. $p<.01$, respectively; $d f=4$ ). Although the difference between the 0 -volt and 30-volt groups is not statistically significant in number of trials to criterion, the difference between these groups with respect to mean second's per trial to criterion is highly significant.

With regard to the five extinction trials, neither total climbing time nor mean second's of climbing statistically differentiated the groups. The latter values are given in Table 1.

\section{Diseussion}

Passive avoidance, in the form of a suppression of the turtle's natural response to climb from a walled enclosure, was obtained without difficulty, and shown to vary with shock intensity in a negatively accelerated manner. The persistence of this response is reflected in the high mean second's per trial for Ss in the 0-volt

TABLE I

Mean Number of Seconds per Trial for each Shock Group in Five Extinction Trials

\begin{tabular}{lccccc} 
Group & \multicolumn{5}{c}{ Trial } \\
\cline { 2 - 6 } & 1 & 2 & 3 & 4 & 5 \\
\hline 0-volt & 200.2 & 155.8 & 296.2 & 436.0 & 460.0 \\
30-volt & 161.5 & 279.8 & 310.6 & 550.5 & 238.5 \\
45 -volt & 360.0 & 481.1 & 363.3 & 414.0 & 495.6 \\
60-volt & 458.7 & 724.8 & 380.0 & 651.7 & 326.7 \\
90-volt & 404.8 & 321.3 & 305.1 & 340.7 & 348.0
\end{tabular}




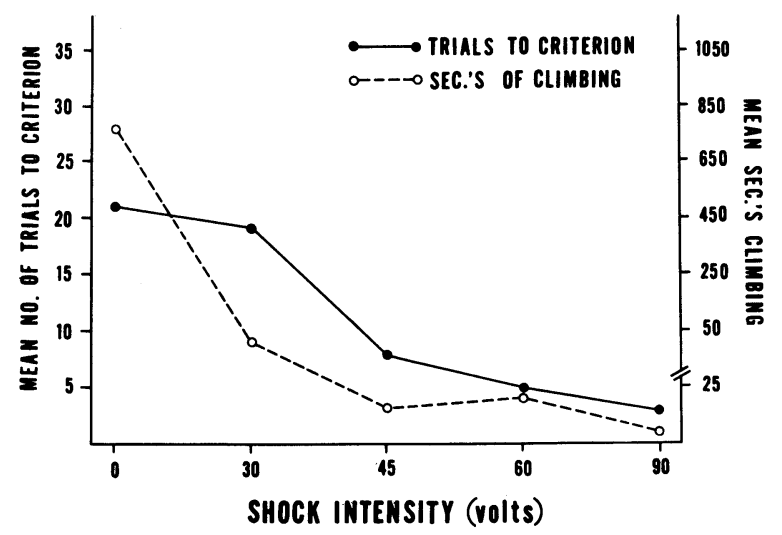

Fig. 2. Functions relating two measures of passive avoidance acquisition to shock intensity.

group, which is in essence an habituation control. One $S$ in this group never did reach zero and could not contribute to the extinction data.

Though two measures of acquisition were found to be sensitive to differential shock level, the five-trial extinction procedure failed to produce differences in mean second's of climbing. It is possible that an extended series of extinction trials may yield differences relating to performance during acquisition.

The need for further study of both extinction performance and the use of shock as an aversive stimulus for the turtle is also suggested by the fact that 0 -volt and 30-volt Ss differed with respect to amount of climbing, as expected, but not in number of trials to criterion. This finding may be analogous to the observation in operant situations of reduction in response rate but not in total number of responses when a mildly punitive stimulus is introduced (Skinner, 1938).

In any case, the procedure described appears entirely feasible for further study of passive avoidance in a reptile species, and especially useful for psychopharmacological investigation.

\section{References}

Spigel, I. M. Detour learning, retention and disruption in the fresh water turtle. J. comp. physiol. Psychol., 1964, 57, 108-112.

Skinner, B. F. The behavior of organisms: an experimental anal$y$ sis. New York: Appleton-Century-Crofts, 1938.

\section{Note}

1. This research was supported by Grant No. MH-08679 from the USPHS.

2. Now at the University of Toronto 